\title{
Sex Roles: An Up-to-Date Gender Journal with an Outdated Name
}

\author{
Janice D. Yoder ${ }^{1}$
}

Published online: 4 December 2015

(C) Springer Science+Business Media New York 2015

I come to Sex Roles: A Journal of Research as only its fifth editor across its 41-year-old history, following Editors Katz (1975-1990); Zalk (1991-2001); Chrisler (2002-2006), and Frieze (2007-2015). Like most incoming editors, I want to build on the scholarship and practices these past editors have so expertly nurtured, as well as keep the journal at the cutting edge of our fields. I come to this position with my own track-record as the former editor of Psychology of Women Quarterly (2010-2015). Although I certainly acknowledge that where my term as editor of Sex Roles will ultimately take me is necessarily unknown, at this launching point I do have some (a) general directions and (b) practiced and projected practices that I want to share here with prospective contributors to the journal, including authors and reviewers.

\section{General Directions}

Every journal succinctly lays out its aims and scope, and these necessarily evolve across time and editors. Mine, and those of my predecessors, say a lot about our expectations regarding what is, and what is not, within the domain of appropriate content for Sex Roles. Let me start here with my own statement of Sex Roles' aims and scope, and then go on to unpack it and

Janice D. Yoder

jyoder34@kent.edu

305K Lowry Hall, College of Public Health, Kent State University, P.O. Box 5190, Kent, OH, USA explain its evolution, intentions, and implications for my editorial practices.

Sex Roles: A Journal of Research is a global, multidisciplinary, scholarly, social and behavioral science journal with a feminist perspective. It publishes original research reports as well as original theoretical papers and conceptual review articles that explore how gender organizes people's lives and their surrounding worlds, including gender identities, belief systems, representations, interactions, relations, organizations, institutions, and statuses. The range of topics covered is broad and dynamic, including but not limited to the study of gendered attitudes, stereotyping, and sexism; gendered contexts, culture, and power; the intersections of gender with race, class, sexual orientation, age, and other statuses and identities; body image; violence; gender (including masculinities) and feminist identities; human sexuality; communication studies; work and organizations; gendered development across the life span or life course; mental, physical, and reproductive health and health care; sports; interpersonal relationships and attraction; activism and social change; economic, political, and legal inequities; and methodological challenges and innovations in doing gender research. The journal also publishes invited book reviews that address gender-relevant topics.

The history of Sex Roles (see Chrisler 2010) reflects the history of the study of gender since the 1970s. Its name itself harkens to that time when scholars across the social and behavioral sciences were countering the dominant paradigm of biological determinism with the functionalist approach promised by exploring "sex roles," that is, the "practices and identities into which people are socialized" (Pascoe and Bridges 
2016, p. 7; also see Carrigan et al. 1985). Editor Katz's (1991) final summary statement about the aims of scope of the journal captures this emphasis: "Sex Roles: A Journal of Research is a forum for the publication of original research articles and theoretical manuscripts concerned with the basic processes underlying gender-role socialization in children and its consequences." Editor Chrisler (2010, p. 300) notes that the name Sex Roles was chosen because "it broadly encompassed psychosocial aspects of people's lives, personality, development, and behavior." Certainly this then innovative approach to thinking about sex roles over biological, dimorphic sex propelled the field forward, with Sex Roles proving to be an invaluable resource across a wide range of topics and across social and behavioral science disciplines.

Starting with the contradiction inherent in the term "sex roles" itself, which blends the biology of sex with the psychosocial concept of roles (Unger 1979), sex roles theory gradually was undermined more fundamentally throughout the 1980s (see Pascoe and Bridges 2016). This evolution in thinking made its way into editors' aims and scope statements for Sex Roles, with Editor Zalk (1991) focusing on "the underlying processes and consequences of gender role socialization, perceptions, and attitudes" and Editors Chrisler (2002) and Frieze $(2015$, p. 1) refining this call to "gender role socialization, gendered perceptions and behaviors, and gender stereotypes." This continual re-positioning of the aims and scope of Sex Roles itself is testimony to one of the core understandings that helped unravel sex role theory, that is, that gender is a product of social structures as well as participates in the shaping of those structures (see Pascoe and Bridges 2016). Thus gender is a complex, dynamic construct that changes across time and is different across cultures (for example, see Kimmel 2012).

As an editor, I owe it to potential authors and our peer reviewers to take a stab at defining what scholarship is appropriate for Sex Roles, recognizing that the journal's very name is outdated (see Frieze and Chrisler 2011) whereas its contents must continue to be up-to-date. My best attempt at this point in time defines the journal's purview as exploring "how gender organizes people's lives and their surrounding worlds, including gender identities, belief systems, representations, interactions, relations, organizations, institutions, and statuses." I purposively want to capture both the individual and the structural in this definition, as well as span disciplines and levels of analysis from the individual, mirco level through the meso, interpersonal to the macro, societal levels. What I find truly exciting with Sex Roles is the breath of the disciplinary perspectives it captures while always focusing in on understanding gender and gendered contexts. This wide scope, along with a coherent focal point, cuts across the many topical areas that appear in its pages - a list that I compiled largely from the papers that have appeared in the journal over the past few years. I do recognize that this list is not exhaustive and that it takes a snapshot of a point in time that will likely evolve across the issues that will be published during my term, but it does help define the journal's contents to date.

My attempt to lay out the purview of the journal by focusing on gender and gendered contexts brings with it several understandings. First, because gender is a social construction, it is culturally embedded and intersects with other identities and social statuses. For these reasons, I, like my predecessors (Frieze 2015; Frieze and Dittrich 2010), want to reach out beyond the United States and other "western" countries to have a global presence and to consistently make clear the cultural context in which each project is embedded. I encourage authors to submit papers specifically focused on the intersectionality of gender with other social statuses and identities (e.g., race, ethnicity, class, age, and sexuality), as well as to be always upfront about the limitations of their sampling and the implications of those limitations.

Second, because human lives are organized by gender, studying gender is not synonymous with solely studying women and women's lives (Pascoe and Bridges 2016). Gender is a major means through which individuals' identities, relationships, power structures, privilege, and inequality are reproduced, extending to all human beings and oftentimes being played out in disparate ways within groups. For example, as Pascoe and Bridges (2016) sagely point out, what makes one a man is not a single form of masculinity but rather a broad spectrum of masculinities with varying degrees of privilege attached to them. As Editor Chrisler (2010, citing Cochran 2010) notes in her history of Sex Roles, founding Editor Katz's inclusion of men on her Editorial Board, an early classic article on men's roles (Pleck 1975), and of "masculinity" as a soughtout topic helped legitimate research in men's studies.

Third, I contend that the simple documentation of sex or gender differences is not appropriate for Sex Roles. Although uncovering a gender difference may make a worthwhile contribution to a topical journal (for example, by raising red flags about the generalizability of an effect), papers published in a journal like Sex Roles, which focuses specifically on understanding gender and gendered contexts, need to do more than document differences. For example, these papers can expose the mechanisms that produce found differences by exploring mediated models and/or qualify the contexts that magnify or mute differences by examining moderated models. Additionally, found differences might be fruitfully linked to different outcomes for individuals based on their identities or contexts that help reinforce and perpetuate gendered systems of social inequality.

Editor Katz in 1991 described Sex Roles as "cross-disciplinary," specifically calling for "pertinent investigations from the areas of psychology, psychiatry, sociology, anthropology, education, political science, and social work." Although an "interdisciplinary" focus was encouraged by all subsequent editors, Editor Chrisler's (2010, p. 304) review acknowledges that the four editors to date were psychologists (as am I) and 
that "submissions written from a psychological perspective have dominated the pages of Sex Roles. Other fields frequently represented in the journal are sociology and anthropology, management, communications studies, human development and family studies, and medicine/nursing." I specifically define Sex Roles' aim and scope as "multidisciplinary," that is, made up of multiple disciplines, and like Editor Katz have reached out to my Editorial Board to back up this claim.

Furthermore, because Sex Roles is multidisciplinary, it is necessarily multi-methodological, spanning quantitative (including content analyses), qualitative, and mixed-methods work. Although the most common methodologies represented in Sex Roles include experiments, surveys, and interviews (Chrisler 2010), its methodological breath has been wideranging and has changed across time. My hope and projection is that we will see more qualitative and mixed-methods work published during my term as these approach grow in their sophistication and are more widely adoption by contemporary researchers. As always, the driving force behind any researcher's methodological choices should be to use the tools best suited to effectively address their research question. Similarly, the driving force behind any manuscript's length should be what is needed to fully report its contributions, methods, and findings so that, although I do appreciate conciseness, I do not plan to enforce one-size-fits-all page limits. And, although reports of original research will continue to dominate in the pages of Sex Roles, I also welcome "original theoretical papers" that argue for exciting, new directions for research and "conceptual review articles" that offer new, integrative frameworks that bring together existing theory and research programs. Thus the thread that I see running through all papers published in Sex Roles is that they are scholarly, that is, they work to move our understandings of gender and gender contexts forward.

This litmus test that a paper published in Sex Roles works to advance a field of study helps define for me what I expect of psychometric work. Although competent work that meets disciplinary psychometric standards is necessary, it is not in itself sufficient to merit publication in Sex Roles - a journal focused on understanding gender and gendered contexts, not measurement per se. Rather a strong, clear case must be made for how a new measure will help researchers better assess the complex construct of gender (Moradi and Parent 2013) or advance an area of study that has implications for people's gendered lives. These latter projections will be strengthened to the degree that some preliminary empirical findings beyond the psychometric development of the measure are offered.

Finally but not unimportantly, although all the editors of Sex Roles identify/fied as feminists (Chrisler 2010), Editor Chrisler (2002) was the first to explicitly refer to Sex Roles as a "journal with a feminist perspective" in her statement about its aims and scope. This criterion recognizes the ubiquity of values throughout our scholarship. It specifies that those values are feminist, that is, if not actively pursuing, at least not antithetical to, a social justice movement to end sexist oppression (hooks 2000). Furthermore, I firmly believe that by stating our feminist values upfront, we necessarily take on added responsibilities to do high quality scholarship that is well within the standards of our disciplines and to make that research, as much as possible, of value to a wide range of practitioners (including therapists/counselors, activists/social policymakers, instructors, and organizational administrators) as well as to students and the general public (Yoder 2015).

\section{Practiced and Projected Practices}

In my first issue as editor of Psychology of Women Quarterly $(P W Q)$, I laid out my expectations for papers submitted to a feminist journal focused on psychology and women (Yoder 2010). In retrospect, this was a much easier task than what now lies ahead of me with Sex Roles. More than ever, as a social psychologist trained in psychology whose own work has been confined to the United States and draws on limited quantitative sophistication, I think my core challenge as editor of Sex Roles will be to know what I do not know. Given the general directions I outlined in the prior section, I want to concentrate in this section on how I plan to realize the aims I seek and handle the broad multi-methodological and multidisciplinary scope they entail.

There are two practices that I followed at $P W Q$ that I have carried over to Sex Roles. First, I recruited three "Consultants to the Editor" who are methodological experts: Sharlene Hesse-Biber (Sociology, Boston College), whose expertise lies in qualitative research and mixed-methods designs, and Cirleen DeBlaere (Education and Human Development, Georgia State University) and Matthew Hesson-McInnis (Psychology, Illinois State University), both of whom are broadly versed in quantitative methodologies. Their input will help insure the high methodological quality of the scholarship we publish as well as lend some consistency across papers. They explore some "best practices" that they expect to find in submissions in their editorials that follow mine in the present issue (DeBlaere and Hesson-McInnis 2016; Hesse-Biber 2016). My goal is to publish state-of-the-art research that fully covers the wide range of methodologies that gender researchers use, including content analyses, qualitative work, and mixed-methods designs.

Second, as I did at $P W Q$, I will routinely ask all authors to try as much as possible to include a subsection in their Discussion section devoted to exploring the "Practice Implications" of their findings. My goal is to address our feminist imperative to engage in scholarship that makes a difference (Yoder 2015). As scholars, we produce well-vetted work that needs to better inform the public discourse by being accessible to people who can use it, ranging from professional practitioners (e.g., therapists/ 
counselors, activists and policymakers, instructors, organizational decision-makers) to students and the general public.

Probably the most daunting aspects of Sex Roles for me are its monthly publication along with the workload this entails and its international, multidisciplinary, and gender (not women) scope. I project handling these challenges with the aid of the Editorial Board. If you take a look at this issue's masthead, you will find a list of Board members along with their disciplinary and university affiliations. I recruited members individually to this Board based on the quality and timeliness of their peer reviews, as well as collectively to span disciplines and topics. Thus this list intentionally includes women and men, U.S. and international scholars, and a wide range of social and behavioral disciplines. Given my focus on gender and understanding gendered processes, I am open to singlegender research, and I will not routinely require that submissions test for gender differences. I also will ask authors to appropriately use the terms "sex" and "gender" so that they are consistent with how each was operationalized.

Beyond the simple composition of this Board, I recruited its members to sign on to a somewhat different plan for their involvement. They and I expect their expertise and advice to be sought out mainly after the first round of reviews have been completed. Thus these Board members will function like "advisory editors" (p. 226 of the American Psychological Association's, 2010, Publication Manual) in that they will be privy to both the submission and reviewers' comments, as well as authors' revision notes when applicable. Although all decision-making will ultimately reside with me as editor (as is required practice; again, page 226 of APA's, 2010, Publication Manual), their oversight will better represent their disciplines, and I expect it to help streamline the revision process. My goals are to be better able to limit the number of reviewers brought into the revision process by rarely needing to go beyond the initial peer reviewers and a Board member, to have more definitive and clear directions for authors to follow as they revise, and to fill in the gaps in my own areas of expertise. In sum, I am striving for a more streamlined yet well informed review process.

To help expedite the review process, I am asking reviewers to submit their comments within 3-4 weeks (but, of course, with some leeway as needed in order to recruit the best experts for each paper). Although I will continue to initially screen papers prior to sending them out for peer review, only in exceptional cases will I ask an author to make revisions prior to seeking peer review. I do regard reviewing not only as a way to select high quality papers for publication but also as a means for providing mentoring - especially to novice authors and those for whom English is not their native language (also see Frieze 2015). Sometimes this latter philosophy calls on reviewers to comment on papers with unlikely prospects for being published. Providing constructive feedback is an important part of peer review, especially in a journal that openly takes a feminist perspective that I think includes nurturing future research and developing researchers.

I also updated the list of classifications from which authors choose to define the topical areas of their paper and from which reviewers specify their topical areas of expertise. I draw heavily on these classifications to match submissions with appropriate reviewers. For example, some of these classifications (e.g., "communication") were too broad to capture specific areas within this broad categorization (now specified as communication: group, interpersonal, media, organizational, and political). Others were outdated (e.g., domestic violence-now intimate partner violence; male roles-now masculinities), still others were missing (e.g., caregiving/helping/altruism), and others were too narrow and thus were meaningfully combined (e.g., parenting/motherhood/fatherhood/attachment). My hope is that these classifications will be more responsive to and representative of the multiple disciplines covered in Sex Roles, as well as capture a snapshot of contemporary topical coverage.

\section{Conclusion}

Although I know that my practices, like this field, are likely to evolve across the course of my term as editor of Sex Roles, I do hope that the present notes offer some transparency regarding my editorial practices along with their rationale and goals. I am fortunate in that, thanks to the editors who have come before me, I have a solid base on which to build. My first step in assuming this new role as editor was to look back at how each editor defined and executed their aims for the journal. My approach at $P W Q$ and now here at Sex Roles is to learn from what has come before me and to grow from what lies ahead. It is in that spirit that I asked Springer to design the new cover which integrates the colors of the original cover chosen by founding Editor Katz with the more contemporary design initiated by Editor Frieze. It is in this spirit that I am looking forward to taking the journal with the outdated name of Sex Roles into an up-to-date and continually evolving future.

\section{References}

American Psychological Association. (2010). Publication manual of the American Psychological Association (6th ed.). Washington, DC: American Psychological Association.

Carrigan, T., Connell, B., \& Lee, J. (1985). Toward a new sociology of masculinity. Theory and Society, 14, 551-604. doi:10.1007/ BF00160017.

Chrisler, J. C. (2002, January). Aims and scope statement. Sex Roles, 46, inside back cover. 
Chrisler, J. C. (2010). In honor of Sex Roles: Reflections of the history and development of the journal. Sex Roles, 63, 299-310. doi:10.1007/ s11199-010-9826-y.

Cochran, S. V. (2010). Emergence and development of the psychology of men and masculinity. In J. C. Chrisler \& D. R. McCreary (Eds.), Handbook of gender research in psychology (Vol. I): Gender research in general and experimental psychology (pp. 43-58). New York: Springer.

DeBlaere, C., \& Hesson-McInnis, M. (2016). Editorial: Some guidelines for publishing quantitative research in Sex Roles. Sex Roles, 74. doi: 10.1007/s11199-015-0569-7

Frieze, I. H. (2015). Final editorial. Sex Roles, 73, 459-460. doi:10.1007/ s11199-015-0555-0

Frieze, I. H., \& Chrisler, J. C. (2011). Editorial policy of the use of the terms "sex" and "gender." Sex Roles, 64, 789-790. doi:10.1007/ s11199-011-9988-2.

Frieze, I. H., \& Dittrich, S. (2010). Sex Roles is 35! Sex Roles, 62, 1. doi: 10.1007/s11199-009-9720-7.

Hesse-Biber, S. (2016). Editorial: Qualitative or mixed methods research inquiry approaches: Some loose guidelines for publishing in Sex Roles. Sex Roles, 74. doi:10.1007/s11199-015-0568-8

hooks, B. (2000). Feminism is for everybody: Passionate politics. Brooklyn: Sound End Press.

Katz, P. A. (1991, June). Aims and scope statement. Sex Roles, 24, inside back cover.
Kimmel, M. (2012). Manhood in America: A cultural history (3rd ed.). New York: Oxford.

Moradi, B., \& Parent, M. C. (2013). Assessment of gender-related traits, attitudes, roles, norms, identity, and experiences. In K. F. Geisinger (Ed.), APA handbook of testing and assessment in psychology (Vol. 2): Testing and assessment in clinical and counseling psychology (pp. 467-488). Washington, DC: American Psychological Association.

Pascoe, C. J., \& Bridges, T. (2016). Exploring masculinities: History, reproduction, hegemony, and dislocation. In C. J. Pascoe \& T. Bridges (Eds.), Exploring masculinities: Identity, inequality, continuity, and change (pp. 1-34). New York: Oxford.

Pleck, J. H. (1975). Masculinity-femininity: Current and alternative paradigms. Sex Roles, 1, 161-178. doi:10.1007/BF00288009.

Unger, R. K. (1979). Toward a redefinition of sex and gender. American Psychologist, 34, 1085-1094. doi:10.1037/0003-066X.34.11.1085.

Yoder, J. D. (2010). Editorial: A feminist journal at the cutting edge of a psychology of women. Psychology of Women Quarterly, 34, 1-4. doi:10.1111/j.1471-6402.2009.01535.x.

Yoder, J. D. (2015). Looking backward and moving forward: Our feminist imperative to do work that matters. Psychology of Women Quarterly, 39, 427-431. doi:10.1177/0361684315601861.

Zalk, S. R. (1991, July). Aims and scope statement. Sex Roles, 25, inside back cover. 